\title{
INTRODUCCIÓN
}

\section{EL MALESTAR DE LA MUJER COMO MOTOR DEL PSICOANÁLISIS}

Blanca Doménech Delgado

El objeto de estudio del psicoanálisis es el inconsciente. Aunque este objeto de estudio está relacionado con la subjetividad en tanto que alude al funcionamiento individual de cada sujeto, el psicoanálisis NO es una psicología, puesto que no analiza sólo la psique de un sujeto consciente que da cuenta de sí, de su historia, de su memoria, sus miedos, preocupaciones, intereses, etc. Y aunque toda persona nace en un contexto social e histórico determinado y es fruto de las experiencias de sus padres, de los modelos sociales vigentes, de la economía, de los más de veintiún siglos de ideas que nos preceden, el objeto de estudio del psicoanálisis no es tampoco coincidente con el de la historia de los pueblos, la sociología ni con la psicosociología. Aunque la psique se sustente en un cuerpo, un organismo biológico, un cerebro, una anatomía, un funcionamiento fisiológico, neurológico, etc., el objeto de estudio del psicoanálisis no es tampoco una psiconeurología. En tanto que mamífero, el ser humano está dentro de una escala biológica, y su comportamiento parecería regido por unos instintos determinados genéticamente, pero en tanto que humano se ha producido un "cambio" que hace imposible hablar de instintos y que exige tener en cuenta otro modo de funcionamiento: el regido por la vida pulsional ${ }^{1}$. En el ser humano no sólo intervienen los instintos de autoconservación de la vida, hay "algo más” que el psicoanálisis ha definido como "pulsión”, que no es innato ni surge genética o espontáneamente o desde un solipsismo.

\footnotetext{
${ }^{1}$ En aquellos dramáticos casos en los que un ser ha sobrevivido fuera del ámbito de la cultura humana, y ha logrado satisfacer sus necesidades vitales, sin embargo no se ha constituido un ser con las atribuciones que permitan calificarle de "humano".
} 
La pulsión nace por la intervención sobre el recién nacido de otro adulto ya constituido con una sexualidad inconsciente de la que no sabe pero que está presente cuando proporciona a ese bebé los cuidados que precisa para vivir. Un adulto escindido que deposita - sin saberlo- no sólo aquello de lo que es consciente sino aquellas otras experiencias, expectativas, anhelos, temores, etc., que subyacen a su saber consciente; aquello indecible que quedó fuera de toda comunicación consciente. Un adulto que cuando atiende, alimenta, asea, toca, mece, arrulla, etc., lo hace, repito, no sólo desde su psiquismo consciente, ni exclusivamente desde los modos culturales trasmitidos por las experiencias habidas con sus padres, abuelos, etc., lo hace desde aquello inconsciente de lo que no puede hablar y para lo que no encuentra explicación (porque tampoco tuvieron explicación aquellos que cuidaron de él). Un adulto que cuida, que aplaca y satisface una necesidad vital, pero que desliga, inquieta y excita al trasmitir "otra cosa" que va más allá de la satisfacción de dicha necesidad. Un adulto que trasmite lo que Laplanche (1987: 128) denomina "significantes enigmáticos" que exigen que ese nuevo ser ponga en marcha una búsqueda, una respuesta a esa inquietud generada en el mismo lugar en donde se instala el placer de la satisfacción de la necesidad. El bebé, en adelante, ya no persigue simplemente un alimento sino deshacerse de esa otra excitación generada en el mismo punto. El infans anhela descargar toda tensión que acompañó al alimento y, además, insiste en repetir y repetir para reproducir de forma idéntica la experiencia de satisfacción primera pero que, al depender de otro que se la proporcione, deberá articular su demanda con la demanda del otro. La madre "supone" que ese bebé quiere algo y, desde su posición como ser experimentado, prueba, tantea, ensaya conductas que acallen los gritos infantiles, que aplaquen su inquietud, que satisfaga lo que imagina es su necesidad (pero que ya no es sólo una necesidad orgánica, sino algo más: la búsqueda de un goce sin límite, una descarga de toda tensión, un estado de adecuación y de relajación absolutas). Esto es, la madre desde su propia historia y experiencia se pone a pensar qué quiere ese recién nacido. Se pregunta ${ }^{2}$ no sólo por lo que le pasa a ese bebé,

\footnotetext{
${ }^{2}$ Cuestionamiento que no necesariamente es consciente, pero que subyace a toda relación con el
} 
Introducción. El malestar de la mujer como motor del psicoanálisis

sino también por lo que ese niño reaviva y significa para ella; una madre que se cuestiona acerca de qué espera de él, qué vacío viene a llenar, por qué deseó tenerlo, con quién deseó tenerlo, qué significa para ella la pareja con la que contribuyó a su gestación, etc. Un adulto para quien ese bebé que llora moviliza inconscientemente toda su historia. El nuevo ser se constituirá en virtud de esa primera dependencia no sólo de un adulto que proporciona cuidados autoconservativos, sino del deseo inconsciente de aquel de quien depende, de las vivencias de ese adulto y del tipo de relación que establezca con él, de las expectativas, palabras, mensajes que le dirige.

Cada nuevo ser conforma su psicología consciente pero también su ser inconsciente, y éste no nació con él, lo construye en esa misma vinculación con sus padres (y con la ley por ellos trasmitida que regula y limita el goce absoluto pero permite un placer "dentro de un orden", la ley que rige la forma de vincularse los seres humanos, la ley que dice qué se puede desear, quién puede o no ser objeto de nuestro deseo; la ley que regula las relaciones entre generaciones y que prohíbe el incesto). Esto es, el recién nacido nunca está solo con su adulto materno ${ }^{3}$. La estructura cultural está presente antes de que el bebé nazca. Y la estructura cultural es patriarcal, más allá de las diferentes manifestaciones que en uno $u$ en otro momento o lugar histórico se puedan dar.

El psicoanálisis investiga los efectos que la cultura y una estructura patriarcal producen en la instauración y configuración del inconsciente. Es el descubrimiento de Freud, y se le hace evidente, con mayor o menor dificultad, a través de lo que las mujeres le decían. Mujeres que manifestaban una problemática en íntima relación con la cultura a la que pertenecían. La importancia del descubrimiento freudiano es desvelar los profundos efectos que la cultura produce en los seres humanos, tengan una u otra

hijo. Ignorar esta pregunta en su totalidad implica no reconocer al hijo como un ser humano deseable, sino como puro conglomerado de células.

${ }^{3} \mathrm{Da}$ igual que sexo tenga ese adulto que cumple esa función, si bien lo llamamos "materno" y lo relacionamos con "madre" y con una "mujer" porque ello ha sido así mayoritariamente durante más de veinte siglos. Pero no siempre fue así; la antropología puede ayudarnos a saber quién o quienes han desempeñado esa función 
anatomía. Freud muestra la ruptura radical con el mundo instintivo animal, con la adecuación perfecta entre lo que se desea y lo que se encuentra, con el saber natural del instinto. Descubre un cuerpo pulsional - no endógeno- cuyo funcionamiento deja de ser acorde al instinto autoconservativo para pasar a ser fantasmático. La realidad psíquica, representacional, no se ajusta como una fotocopia a la realidad material externa. Y ello es así por efecto de la intromisión de la sexualidad inconsciente del otro.

El ser humano es un ser que inconscientemente fantasea, que representa y crea el objeto que supone calmará toda insatisfacción. El objeto que simbólicamente se representa y crea no existe, como un calco, por fuera de él. Tampoco es un ser adaptativo, en armonía con la naturaleza, capaz de obtener la felicidad plena, el objeto anhelado. Aunque el ser humano trae unas disposiciones orgánicas (capacidad para respirar, para succionar, para digerir, para gritar, etc.) no viene dotado de un aparato psíquico. Y éste ha de construirlo y no surge sólo como adaptación, sino como alucinación pues, como he expresado, trata de resolver algo de la economía psíquica inconsciente y no sólo del orden de la necesidad biológica. El ser humano es el único que puede ansiar y gozar con cosas que le dañan, que no le ayudan, que persiste en "lo malo conocido", que repite una y otra vez sus mismos errores -aún disponiendo de una inteligencia y capacidad para reflexionar sobre la estupidez de sus acciones. Porque el propio pensamiento yoico no es ajeno a un procesamiento primario regido por la repetición mortífera y por el placer. La insatisfacción o la imposibilidad se instalan para garantizar seguir viviendo y soñando con "algo más" que, por fin, se ajuste perfectamente con lo fantaseado y largamente deseado. Muchos de los objetos anhelados serán valiosos pero nunca suficientes. El ser humano es un ser deseante y desear es un puro movimiento que nos habla de una estructura en falta ${ }^{4}$, de ese "plus" pulsional que se instauró en el origen de la vida, de esa armonía instintiva perdida. Y en lo que respecta a la sexualidad genital no iba a ser de otra manera. Para el ser humano,

\footnotetext{
${ }^{4}$ El deseo apunta a una relación privilegiada con un objeto (con atributos aportados por el objeto: la voz, el contacto, el olor, la temperatura, el movimiento, la imagen, etc.), pero no va a la búsqueda de la satisfacción de una necesidad ni a la posesión de un objeto exterior.
} 
Introducción. El malestar de la mujer como motor del psicoanálisis

según el psicoanálisis, no hay un ajuste hombre-mujer ${ }^{5}$. No está definido que el objeto de uno haya de ser la otra y viceversa, ni siquiera que haya de ser un adulto, u otro ser ajeno a uno mismo. Lo construirá en su historia, pero no sólo en una historia real, sino en la fantasmática. Pero tampoco existe un hombre o una mujer constituidos de entrada, también habrán de posicionarse como tales en el transcurso de su devenir fantasmático. “La anatomía es el destino", dirá Freud (1924: 185) parafraseando a Napoleón, pero porque sobre la anatomía se construye el fantasma. La diferencia anatómica corporal existe (lo contrario sería una negación de la realidad y evidenciaría algo mucho más grave) pero el cuerpo depende de cómo se vivencie, de qué interpretación se haga de él, de qué se diga. Y esto se produce en los primeros años de vida construyendo un inconsciente que no deja de existir porque, a posteriori, se disponga de una razón o de un Yo. El funcionamiento propio del pensamiento consciente, del Yo, no es ajeno al inconsciente. El ser pulsional del que habla Freud -sea hombre o mujer-construye la realidad a pesar de ella misma o incluso en contra de ella misma.

Parece algo evidente que cada área de saber ha de definir cuál es su objeto y cuál su metodología. Pues bien, el objeto de estudio del psicoanálisis es peculiar y propio de este campo del saber, diferente de la psicología, la sociología, la antropología, la ética, la psiconeurología, etc.: es el inconsciente. Es decir, aquello de lo que el Yo de cada persona no puede dar cuenta porque lo desconoce, aunque produce efectos que ese mismo Yo es capaz de captar. Pero el inconsciente no es una subconciencia de inferior valor lógico, ni un error de juicio sino que tiene sus propias leyes de funcionamiento. La obra de Freud no es lineal ni acumulativa ${ }^{6}$. El propio pensamiento freudiano no es ajeno

\footnotetext{
${ }^{5}$ Freud en "Tres ensayos de teoría sexual" (1905: 202-214) defiende la tesis de que no hay una armonía establecida ni complementariedad entre los sexos, que se requiere un largo período hasta la elección del objeto de amor, que no existen carriles del libre acceso del hombre a la mujer y viceversa o, como diría Lacan (1956-57: 51), no hay el chico y la chica, "el hilo y la aguja".

${ }^{6}$ Caben varias lecturas -biológica, psicológica, sociológica- de la obra de Freud, y todas ellas apelando sin incorrección a sus textos, puesto que él mismo se "extravía" o tiene dificultades en hacerse cargo de aquello que está descubriendo, de este nuevo objeto de estudio.
} 
al funcionamiento inconsciente. La repetición, la represión (inherente al pensamiento yoico y por tanto también al de Freud), el olvido, el retorno de lo reprimido, la negación, etc., están presentes en su pensamiento, en sus textos. Freud descubre un nuevo campo de estudio, una realidad virgen, un terreno inédito. Como hace notar Gutiérrez Terrazas (2002), su obra supone un profundo desgarramiento conceptual respecto del pensamiento que le precede y rodea. Ello supone una dificultad enorme a la hora de reflexionar sobre este edificio teórico. Pero también hay que decir que se ha hecho una utilización -desde las propias filas del psicoanálisis- que hace decir a Freud lo que no dice por haberse sacado de contexto frases sin apelar al conjunto de su obra, por haberse hecho una interpretación pre-freudiana de su pensamiento, por haber interpretado o entendido sus conceptos sólo bajo acepciones psicológicas, sociológicas, biológicas, pero no psicoanalíticas". Además, como muestra Laplanche en "Vida y muerte en psicoanálisis" (1970), en "La prioridad del otro en psicoanálisis" (1992) y en “El extravío biologizante de la sexualidad en Freud" (1993), el pensamiento freudiano no es un bloque homogéneo sin contradicciones. Freud ha hecho, en un plazo menor de cincuenta años, una auténtica revolución copernicana respecto al pensamiento que le precede, pero ello con enormes trabas provenientes de las propias dificultades para asimilar y entender lo que está descubriendo. Si hay un Copérnico, en Freud también existe Ptolomeo. La revolución copernicana ${ }^{8}$ que altera el pensamiento ptolomeico (ateniéndonos a las intuiciones, pensamientos, vacilaciones, "vueltas atrás" que preceden y recogen diversas tradiciones y que finalmente dan pie a las dos posiciones extremas) dura casi dos milenios e intervienen en ella filósofos, astrónomos, teólogos, matemáticos, en definitiva, gran número de pensadores notables. La ingente obra

\footnotetext{
${ }^{7}$ El respeto por otros objetos de estudio no implica que el psicoanálisis sea una interdisciplina. El cuerpo de la mujer y su sexualidad puede ser objeto de estudio interdisciplinar, pero es menester discriminar el campo de cada especialidad. El psicoanálisis no es la suma de otras materias.

${ }^{8}$ Teoría heliocéntrica cuyo origen hay que buscarlo en Aristarco de Samos (siglo III a.C.) pero que será ignorada durante un largo período ptolomeico hasta la aparición en el siglo XV de Copérnico. Esto es, dieciocho siglos después.
} 
Introducción. El malestar de la mujer como motor del psicoanálisis

freudiana ${ }^{9}$-repito- no es ajena a numerosos puntos débiles, contradicciones, vacilaciones, olvidos que van a resultar en distintas posiciones teóricas desde las propias filas del psicoanálisis ${ }^{10}$.

El objeto de estudio psicoanalítico -el inconsciente- no se deja atrapar fácilmente, se sustrae en la medida en que se lo conoce. Y el juicio es el vehículo a través del cual podemos reflexionar, discutir, pensar sobre este objeto de estudio propio. Pero la razón, aunque regida por el proceso secundario y la lógica, no es ajena al proceso primario y su peculiar orden lógico. La razón no es extraña a esos mecanismos que tratan de proteger y garantizar el placer, asegurar la ilusión de control y dominio. El psicoanálisis tiene por misión mostrar los engaños de esa ilusión. El Yo del que debate, cuestiona, etc. tampoco está exento de su propio inconsciente. El psicoanálisis ha precisado de una metodología diferente que, utilizando el lenguaje y el entendimiento, permita ir más allá, hacia esa otra realidad que tiene una singular característica: no dejarse asir. El psicoanálisis tiene su objeto específico: el inconsciente. Que no se deje asir no quiere decir que sea "loco", que no tenga sus propias leyes, que no persigamos la pretensión de lograrlo apelando a la metodología psicoanalítica, a la razón y al lenguaje como los instrumentos fundamentales de que dispone el ser humano para saber de sí y de su mundo. Ahora bien, ese saber de uno mismo está siempre intrincado y dialectizado con el otro y con un "no querer saber". Ese no querer saber remite al orden de lo pulsional. ¿Qué es lo pulsional?

Lo pulsional remite a una búsqueda de un placer más allá de la pura satisfacción de la necesidad orgánica y estimula las fantasías inconscientes. El objeto de la necesidad se pierde en favor de ese otro fantaseado, antinatural, no adecuado ni predeterminado genéticamente, pero insistentemente buscado. Lo pulsional alude a ese mundo fantasmático y auto o aloerótico, generado por el otro.

\footnotetext{
${ }^{9}$ Se le puede "acusar" a Freud de no haber sido capaz de hacer él sólo la revolución copernicana que duró dieciocho siglos y de haber plasmado en su obra sus incertidumbres, extravíos u olvidos. ${ }^{10}$ El psicoanálisis hoy participa, también, de esta dificultad para hacerse cargo de su propio campo y objeto de estudio.
} 
La conflictividad inherente a la sexualidad humana es el gran descubrimiento freudiano y la organización de la sexualidad femenina el punto más arduo e impugnado desde las propias filas del psicoanálisis. Este número está dedicado a presentar - desde posiciones psicoanalíticas diversas- las reflexiones que las autoras hacen acerca de la profundamente "antinatural" o "no instintiva, prefijada o predeterminada" sexualidad humana y específicamente de la sexualidad femenina. Persigue mostrar cómo aunque la sexualidad tiene que ver con la anatomía exige una inscripción psíquica inconsciente que la hace especialmente conflictiva. Dicha inscripción psíquica no viene determinada genéticamente. Es un producto cultural pero se instaura no sólo en la conciencia sino en el inconsciente y siguiendo unas leyes que no responden a la lógica de la consciencia.

Freud descubre el inconsciente escuchando lo que las mujeres histéricas le dicen. Y las cree. No piensa -como se sostenía en la época y se mantiene en la actualidad- que las mujeres que se quejan, que muestran trastornos diversos, simulen. La palabra de la mujer guía a Freud. El "continente negro" se transforma en el motor de sus trabajos. La protesta de la mujer, la pregunta de ella acerca de sí misma y de su deseo, el cuestionamiento, el malestar y la crítica femenina a su situación social no caen en el vacío, ni se transforma en Freud $^{11}$ en una acusación contra ella o en una descalificación. Freud quiere saber sobre la sexualidad femenina. Las mujeres, como recoge Assoum (1994), con su decir hacían presente a Freud que la sexualidad (rasgos, actitudes, funciones adscritas) es una categoría social inhibidora del desarrollo y del crecimiento personal. Una categoría social insuficiente para dar cuenta de lo que una mujer es. No hay un universal que permita definir para siempre la esencia femenina, porque no existe tal esencia. La subjetividad de cada mujer, su identidad sexual, su posición sexual subjetiva, su elección sexual, su particular modo de relación con el

\footnotetext{
${ }^{11}$ Aunque participe de las concepciones teóricas que conformaban el universal Mujer, que pueda subyacer en él una ideología androcéntrica, Freud va más allá de ese universal y escucha a una por una. Gracias a ellas, a la escucha de su queja y su malestar, descubre un inconsciente construido en el seno de una sociedad patriarcal, una sexualidad no instintiva, antinatural, pulsional, simbólica y en inevitable conflicto.
} 
Introducción. El malestar de la mujer como motor del psicoanálisis

mundo y con el goce exigen una respuesta singular de cada mujer ${ }^{12}$. La pregunta y la insatisfacción femenina abren a la verdad y conducen a su búsqueda incesante. Pero no a la búsqueda de una verdad cerrada, delimitada, acabada, muerta.

Con este número se pretende dar cabida a la palabra de aquellas o aquellos que escuchan a las mujeres, a lo que se dice de ellas, a lo que determina lo que somos. Así, nos encontramos con el artículo de Irene Meler que desde una óptica crítica persigue desvelar los sesgos androcéntricos que encuentra presentes en la obra freudiana y exponer los nuevos enfoques teóricos que se están llevando a cabo desde los estudios de género. Cristina Marqués se pregunta si el psicoanálisis lacaniano o los constructos feministas de Firestone y de Haraway pueden hoy en día contribuir o no a la emancipación femenina. Claudia Truzzoli señala cómo la posición devaluada en la que es ubicada la mujer en una sociedad que jerarquiza el género incide sobre su destino sexual y sus malestares. Por su parte, Laura Elena Ferrón apelando al psicoanálisis y al imaginario social mexicano reflexiona acerca de la subjetividad femenina más allá de la pura diferencia anatómica de los sexos. El trabajo de Graciela Strada establece la especial trascendencia que para las mujeres tiene su imagen constituida en esa primera relación especular con la madre, pero sin ignorar la presencia de la aceptadora mirada paterna como tercero simbólico. Subrayando esa especial, intensa y ambivalente vinculación entre madre e hija, María Dolores Navarro apunta hacia "el estrago" que produce el desgarramiento inevitable y necesario entre ambas para acceder a la feminidad propia y presenta la nueva conflictividad y sintomatología de las mujeres que se observa desde la clínica contemporánea. Enriqueta Moreno Orúe cuestiona la mitificación e instrumentalización cultural y social que se ha hecho de la maternidad, anclando a la mujer en un universal, en un único papel e ignorando el resto de los factores que Freud descubre en el desarrollo psicosexual de la niña y que configuran su

\footnotetext{
${ }^{12}$ En este sentido el psicoanálisis puede entenderse en la misma línea que el feminismo de la diferencia; en la medida en que no pretende determinar un universal "Mujer" para interesarse por la verdad del deseo de cada sujeto sexuado ubicado en posición femenina, para desvelar la enorme diversidad existente en la subjetividad de las mujeres.
} 
identidad. Expone las disyuntivas que se le abren a la mujer en el momento actual en virtud de la diversidad de roles que puede desempeñar en nuestra sociedad. Por su parte Irene Fridman, desde una posición reflexiva y crítica, profundiza en las consecuencias psíquicas que se derivan de haber sido víctima de incesto en la infancia comparándolas con aquellas otras formas de violencia y victimización política sufridas por mujeres.

En Tribuna Abierta, Remedios Martínez Verdú expone cómo las aportaciones de la teoría psicoanalítica, las teorías de género y el feminismo han contribuido a la comprensión de la socialización de la mujer. Se destaca aquí la especial importancia que los movimientos de liberación de las mujeres han tenido en este último siglo para entender la subjetividad femenina y cuestionar la rigidez de los modelos culturales propuestos a la mujer sustentados en una supuesta "naturaleza femenina". Por último, en esta misma Tribuna, y desde planteamientos teóricos ajenos al psicoanálisis, el trabajo de Gian Piero Turchi, Martina Sarasin y Simona Fanelli persigue describir desde el paradigma narrativista las modalidades cognoscitivas que contribuyen a la construcción de la mujer toxicómana y analiza en qué medida estas modalidades de construcción de la realidad cambian al transformarse en madre.

No existen esencias naturales, realidades dadas. Lo que el psicoanálisis ha puesto en evidencia es que la feminidad no es un punto de partida sino una posición de llegada. Una posición, un lugar, que ocupa un sujeto, dotado de una anatomía, es cierto; pero ésta por sí misma no determina una sexualidad o una subjetividad masculina o femenina. La realidad inconsciente es efecto del discurso y miramos el mundo, desde unos supuestos de pensamiento, impregnados de contenidos culturales e históricos, mediatizados por la particular experiencia pulsional. "Hablamos porque somos habladas" dice Gómez Valverde (1999: 97); lo que somos, sentimos, pensamos, deseamos, etc., se construye dentro de un mundo que nos precede y rodea, impregnado de lo que han esperado, pensado, soñado, hablado de nosotras. Elegimos nuestra peculiar forma de hablar, de ser, teniendo en cuenta los avatares de nuestra historia real, pero sobretodo fantasmática. Dar cuenta de ello es la pretensión de este monográfico. 
Introducción. El malestar de la mujer como motor del psicoanálisis

\section{BiBLIOGRAFÍA}

Assoun, P-L. (1994): Freud y la mujer. Buenos Aires, Nueva visión. (Versión castellana de Freud et la femme. Calmann-Lévy 1983, 1993).

Freud, S. (1905): Tres ensayos de teoría sexual. (1ª Edición, 1978; $9^{\text {a }}$ reimpresión, 1996). Obras Completas. Buenos Aires, Amorrortu. Tomo VII, pp. 109-224. (Versión castellana de Drei Abhandlungen zur Sexualtheorie).

-(1924): El sepultamiento del complejo de Edipo $\left(2^{\mathrm{a}}\right.$ edición, $1984 ; 7^{\mathrm{a}}$ reimpresión, 1997). Obras Completas. Buenos Aires, Amorrortu. Tomo XIX (Pp. 177-188). (Versión castellana de Der Untergang das Ödipuskomplexes).

Gómez Valverde, L. (1999): "Hablamos porque somos habladas", en Mujeres, humanidades, comunicación y otras culturas, 4. pp. 97-118. Castellón, Fondo Social Europeo. Proyecto NOW. Universitat Jaime I.

Gutiérrez Terrazas, J. (2002): Cómo leer a Freud. Madrid, Síntesis.

Lacan, J. (1956-57): El seminario de Jacques Lacan. Libro 4. La relación de objeto. 1956-1957. (1 ${ }^{\mathrm{a}}$ Edición. $1^{\mathrm{a}}$ reimpresión, 1998). Barcelona, Paidós. (Versión castellana de Le Séminaire de Jacques Lacan, Livre IV. La relation d'objet. Éditions du Seuil, París, 1994).

Laplanche, J. (1970): Vida y muerte en psicoanálisis. (1 $1^{a}$ Edición). Buenos Aires, Amorrortu. (Versión castellana de Vie et mort en psychanalyse. Paris, Librairie Ernest Flammarion, 1970).

-(1987): Nuevos fundamentos para el psicoanálisis. La seducción originaria. (1 Edición. 1ª reimpresión: 2001). Buenos Aires, Amorrortu. (Versión castellana de Nouveaux fondements pour la Psychanalyse. La séduction originaire. Paris: Presses Universitaires de France, 1987).

-(1992): La prioridad del otro en psicoanálisis. (1ª Edición, 1996). Buenos Aires, Amorrortu. (Versión castellana de La révolution copernicienne inachevée. Paris, Aubier). 
- 1993): El extravío biologizante de la sexualidad en Freud. (1 ${ }^{\text {a }}$ Edición: 1998). Buenos Aires, Amorrortu. (Versión castellana de Le fourvoiement biologisant de la sexualité chez Freud. Paris, Synthélabo. Colec. Les empêcheurs de penser en rond. 1993). 